\title{
Assessment of the economic sustainability of an organic olive oil farm in the Puglia Region (Italy) under the voluntary regional quality scheme
}

\author{
Gianluigi Cardone*, Francesco Bottalico*, Moltine Prebibaj**
}

\author{
DOI: $10.30682 / \mathrm{nm} 2101 \mathrm{~h}$ \\ JEL codes: D4, Q17
}

\begin{abstract}
The Puglia region is the most important producer of organic olives in Italy. The study aims at assessing the economic sustainability of a selected organic olive oil farm by adopting and testing the methodology based on a scientific approach designed by CIHEAM Bari, with the collaboration of a group of experts from national and international research organisations, used in the Programme "Agricoltura\&Qualità" of the Puglia Region. A SWOT-analysis of quality schemes'system in Puglia has been drawn. The case study concerns a traditional organic farm producing olive oil, table olives, and almonds in the Puglia region. The SWOT analysis highlights that Puglia has not a fully functioning system to ensure sustainability. However, the results prove the feasibility of the methodological approach to assess the economic sustainability of the farm. Therefore, the farm is economically sustainable and can use the "Economic sustainability" logo, in addition to the organic and PDO logos. Per hectare, almond is the most profitable crop with the highest revenue, variable costs are higher in table olives and inputs are higher in olives for oil. The growing interest in sustainability is an important opportunity to develop the agri-food sector.
\end{abstract}

Keywords: Sustainability guidelines, Organic farming, Olive oil farm, Economic indicators, SWOT analysis.

\section{Introduction}

Nowadays, the sustainability concept is attracting increasing attention due to population growth and the depletion of natural resources. There are different definitions of sustainable development, but the most widely accepted one is from the report "Our common future" released in 1987 by the World Commission on Environment and Development (WCED) chaired by Gro Harlem Brundtland, stated as "development that meets the needs of the present generation without compromising the ability of future generations to meet their own needs". Based on this definition, sustainable development refers to three major components: social equity, economic viability and environmental sustainability. Economic sustainability is defined as the ability to generate a durable growth of economic indicators, notably the ability to generate income and employment for the population's livelihood (Spangenberg, 2005).

\footnotetext{
* International Centre for Advanced Mediterranean Agronomic Studies (CIHEAM Bari), Valenzano (Bari), Italy.

** Agricultural University of Tirana, Tirana, Albania.

Corresponding author: bottalico@iamb.it
} 
Different approaches have been developed with respect to issues of sustainability, including organic farming (Eyhorn et al., 2019). It is continuously emphasising the relationship between the multifunctional role of agriculture (Saker et al., 2018), as well as organic farming, and the concept of sustainability for several reasons. Firstly, organic farming is considered a production method with no negative impact on human health and the environment, while providing a sustainable income to farmers (Reganold and Wachter, 2016; Ramankutty et al., 2018). Furthermore, organic farming may be considered as an optional approach towards sustainability that can sustain agricultural production in the long-term, but it should be adapted to the local conditions and local crops (Šūmane et al., 2018). Local crops provide sustainable production and they are economically feasible for the community (Shelef et al., 2018). Besides their importance as local cultivations (Saponari et al., 2018), olive crops represent one of the most important sources of income and employment for the Italian rural economy (Stillitano et al., 2016), mainly in the southern regions, and they are also one of the key players in supporting rural economies in the Mediterranean region (Iofrida et al., 2020). Organic olive crops in Puglia, in south-eastern Italy, represent $30 \%$ of the total surface allocated to organic olive growing in Italy (SINAB, 2018) Furthermore, it is one of the leading regions in the Italian organic sector in terms of cultivated surface and number of operators, with many hectares of organic crops such as olive, almond, grapes, etc. (SINAB, 2018; Biobank Open Project, 2018). Hence, the organic surface of the Puglia region represents 14\% of the Italian organic surface. The portion of organic agricultural land allocated to organic olives growing represents $27 \%$ of the total olive-growing surface of the Puglia region. The area around Bari, a province of the Puglia region, is the largest producer of olive oil by volume in Italy. In the Bari province the organic surface represents $14 \%$ of Puglia's organic surface. The portion of organic land dedicated to organic olives in the province of Bari represents $24 \%$ of the total organic olive-growing area. Bari represents $32 \%$ of the total organic olive-growing surface area in Puglia (SINAB and Biobank Open Project, 2018).

Actually, more and more attention is being paid to the sustainability of typical agro-food products (Malorgio et al., 2015, Capone et al., 2016). However, while producers give particular importance to economic sustainability, greater weight is given by consumers to the environmental one. As for economic sustainability, it is mainly related to profitability for producers, while consumers associate it with accessible prices. This creates a trade-off between consumers and producers and policy should mediate between the two in order to find a balance between these different sustainability understandings and aspirations of two important actors of the agrofood chain. This is a concrete challenge also for the government of the Puglia region.

The Puglia Region (Regional Government of Puglia) has increasingly focused on measurement tools to assess the sustainability of agrifood production so as to support both private and public decision making, as well as to meet the demand of consumers for high quality and low impact products.

In the framework of the Programme "Agricoltura \& Qualità" of the Puglia Region, the CIHEAM Bari carried out a pilot project with the objective of assessing and promoting the quality and the sustainability of traditional and typical food products through a scientific methodological approach under the voluntary Regional Quality Scheme "Prodotti di Qualità Puglia", in accordance with the Regulation (EU) No 1305/2013. The Regional Quality Scheme (RQS) is a certification that promotes regional quality products, related to plant and animal food products (including fish products) and floriculture. Through specific Production Standards (specifying the characteristics of products and their production process), approved by the Puglia Region, food safety, appropriate agronomic techniques, plant health, animal welfare and environmental protection are ensured ( $\mathrm{Re}-$ gione Puglia, 2016). The International Centre for Advanced Mediterranean Agronomic Studies of Bari (CIHEAM Bari), with the scientific and technical collaboration of sustainability experts 
from several Italian scientific institutions, namely the Italian National Agency for New Technologies, Energy and Sustainable Economic Development (ENEA), the Research Centre on Food and Nutrition (CRA-NUT), the National Research Council (CNR), University of Bologna Alma Mater Studiorum, University of Naples Federico II and the Forum on Mediterranean Food Cultures, set up the optional "sustainability" prerequisite guidelines to assess and promote the sustainability of agri-food products through a scientific methodological approach applying the "additional sustainability logo".

This framework relates to the production system such as farm size, capital, farming activities, agricultural practices and the adoption of technological innovations. Particularly, the voluntary sustainability standard can create added value for small farmers.

The optional "sustainability" prerequisite guidelines, and particularly, the economic sustainability indicators (Capone et al., 2016), were developed in 2015-2016 as a theoretical methodology. Nonetheless, it needed to be implemented in a case study and tested on real data. In this paper, however, it is the first time that the sustainability methodology is implemented using real data from organic farms in the Puglia region in Italy.

The purpose of the present study is to apply a preliminary methodological approach and economic indicators in order to assess the economic sustainability of organic olive oil farming in Puglia. Moreover, a SWOT analysis was performed on the system of quality scheme.

The main objectives of this study are:

1. To analyse the organic olive oil sector in Puglia.

2. To carry out an economic analysis of a pre-selected "traditional organic olive oil farm".

3. To implement and verify the feasibility of the methodological approach under the regional quality scheme "Prodotti di Qualità Puglia" and to assess the economic sustainability of the case study in its territorial context.

4. To evaluate whether the "additional sustainability logo", certified by the Puglia
Region, can be attributed to the selected organic olive oil farm.

5. To apply a SWOT-analysis of regional system of quality schemes (Protected Designation of Origin, Protected Geographical Indication, Organic certification and "Prodotti di Qualità Puglia" promoted by the European Union).

This paper mainly considers the traditional organic olive farm as a case study for the assessment of economic sustainability. This farm is not representative of all farms in general; as a matter of fact, the criteria of selection have been drawn in accordance with the main characteristics of the current and traditional example of olive farming in rural areas in Puglia.

\section{Materials and methods}

To apply the principles of sustainability and to assess the economic sustainability of the selected organic olive oil farm the scientific methodological approach developed in the "Agricoltura \& Qualità" program of the Regione Puglia was adopted. The methodological approach used is in line with the Sustainability Assessment of Food and Agriculture Systems (SAFA) approach, based on the adoption of a hierarchical approach (FAO, 2013) from sustainability themes to indicators for each dimension (Figure 1). The methodology aims to evaluate the sustainability separately for the four dimensions (environmental, economic, socio-cultural and nutritional-health) and each of these dimensions has the same importance as the others. For each sustainability pillar, some criteria were identified and for each criterion some indicators were selected. For this study, an assessment of economic sustainability has been carried out. Thus, specific criteria and indicators were selected to measure the economic sustainability performance in a reliable way at farm level and to determine progress towards sustainability.

The identified criteria of economic sustainability refer to income level and stability, investments, employment, profitability and productivity of production factors. Furthermore, for each criterion some indicators were selected that were suitable and measurable at farm level (Capone 
Figure 1 - The methodological approach from sustainability themes to indicators for each economic dimension.

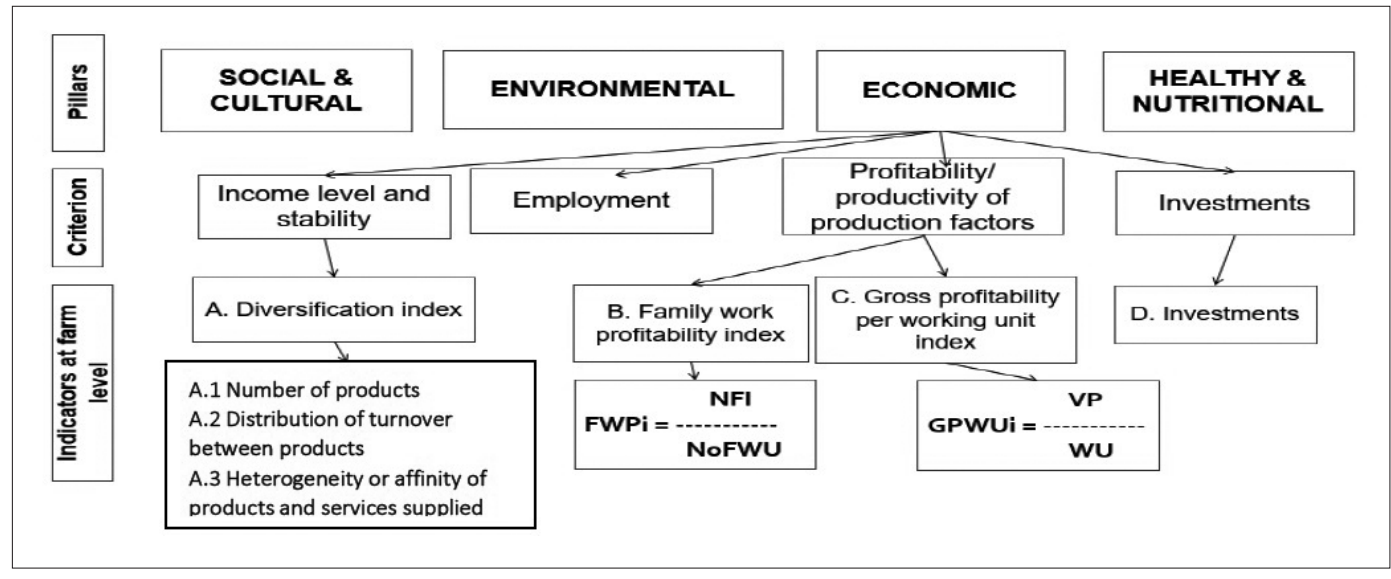

et al., 2016). The economic sustainability indicators used to assess the economic sustainability of organic olive oil farming are described in the Programme in "Agricoltura \& Qualità" of the Puglia Region (Figure 1). The assessment framework can be applied in a different context to evaluate management systems and decisionmaking and to distinguish potential areas of policy interventions. Each selected economic sustainability indicators was calculated according to the calculation method described in the methodology. Then, selected indicators with different units were normalized in relative terms with the appropriate coefficient determined in the programme to have values in the same unit and to make them easier to aggregate.

According to the number of products and services made by the company (A1), when no product is produced, the score is equal to 0 points, if there are 2 products it represents the benchmark and the score amounts to 0.5 points; if there are 4 or more agricultural products the score is $=1$. The score is multiplied by a weighting factor of 0.5 . For the distribution of turnover between the different products and services (A2), values from 0 to 1 are assigned based on the percentage weight of the production value of the first product or extra- agricultural activity. If the first product or non-agricultural activity holds $100 \%$ of the value of the total production of the company, a score equal to 0 is assigned. If the first product or business holds a value greater than or equal to $70 \%$ of the value of the company's production a score of 0.3 is assigned; 0.5 points are given if the first product or activity reaches $50 \%$ of the value of the company's production; 0.7 points are assigned if it reaches $40 \%$ of the production value; 1 point if the first product or activity reaches $30 \%$ of the value of the company's production. The score obtained should be multiplied by a weighting coefficient of 0.2 . In case of the heterogeneity or proximity of the products and services offered (A3): if the company only manages the agricultural activity the score is equal to 0.3 points; if, besides the agricultural one, it carries out another activity, whether it be of transformation or within the framework of multifunctionality, the score is 0.6 points, if in addition to the agricultural one it carries out two activities one point is awarded. The score obtained should be multiplied by a weighting coefficient of 0.3 . The values (derived from the sum of the multiplication of the weighted scores of the three elements) that the DI can take varies from a minimum of 0 (in single-product companies) to a maximum of one. The value of 0.5 is the reference average. In particular, the degree of diversification is accentuated when production increases, with a "balanced distribution of turnover among the various products, and to increase the heterogeneity between the products. This last feature is evidently increased by the introduction of 
the supply of both food and non-food products and services in the company (broadening and deepening).

During this step, scales of measures were converted into a comparable scale. The normalized indicators should be aggregated to obtain the final value which can summarize the information related to the economic dimension. The sustainability benchmark value was defined for each indicator. The sustainability benchmark represents in a numerical form the threshold of sustainability beyond which a product, and/or the company that produces it, can be considered sustainable. This value was defined by CIHEAM Bari with the support of experts from several research institutions, taking into account the average performance of Puglia agri-food companies or national and European Union standards/regulations. Based on the principle of continuous improvement, the sustainability benchmark values will be updated every 5 years. Once the benchmark had been determined, a scoring system was developed for each indicator referring to each product and supply chain; from 0 (unsustainable) to 1 (very sustainable), the benchmark corresponds to the score 0.5 .

The farm, submitted to the Regional Quality Scheme (PdQP) with a sustainability benchmark value at least 0.5 , can demonstrate its submission to the optional "sustainability" prerequisite using the "additional sustainability logo" (Figure 2) written on the product/s complying with guidelines of the Puglia Region (Regulation (EU) No 1305/2013). The enterprise can demonstrate its subscription to the optional "sustainability" prerequisite by applying the "additional sustainability logo" on product/s. The logo is made up of three sustainability dimensions completed with the health-nutritional component. The "additional sustainability logo" guarantees the sustainability of the farm process carried out to grow or produce the product from an environmental, economic, socio-cultural and nutritional health point of view. The procedures for permission to use the "additional sustainability logo" are defined in the guidelines. It can be considered as an innovation protecting the quality of local food products via an interdisciplinary approach taking into consideration environmen-
Figure 2 - Additional sustainability mark (logo).

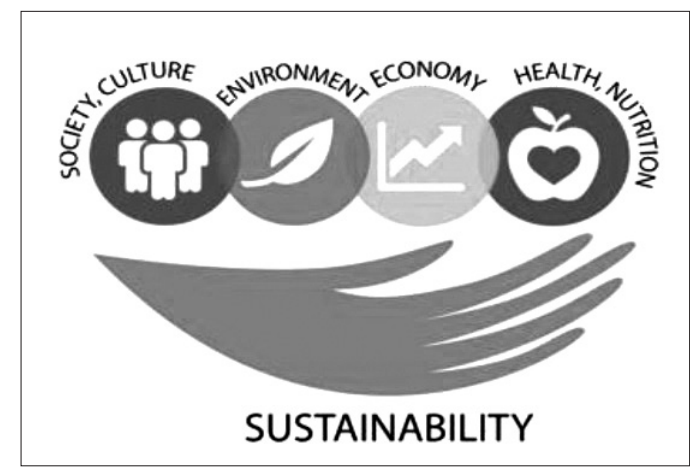

tal issues and various aspects pertaining to food, habits, customs and traditions, health and the community's economic benefits (Capone et al., 2016). The methodological approach can be applied to who demand, as approved by Regione Puglia, the use of the additional "additional sustainability logo" for the products that adhere to the regional quality scheme or to other quality schemes recognized at EU level. It is applicable to a single farm as well as groups of farms joining the Quality Scheme and organized in chains. Hence, the application for the use of the "additional sustainability logo" has to concern four pillars: environment, economy, society-culture and nutrition health (Figure 2).

The Puglia Region assesses the proposal of the farm in relation to the criteria identified in the sustainability guidelines and grants the transitional use of the "additional sustainability logo". Particularly, the logo may be used on the products subjected to the RQS and to the sustainability criteria defined by the sustainability guidelines. In case of partial approach of sustainability, i.e. the product does not comply with all 4 pillars, the "additional sustainability logo" will display only the dimension/s applied, for a transitional phase (one year). However, at the end of the transitional phase, sustainability of the farm will be evaluated for each one of the sustainability pillars (environment, economy, society-culture and nutrition-health) that have equal importance as a subsequent normal phase (Malorgio et al., 2015). After the transitional phase, on the basis of the gained experience, the Puglia Region will define a sustainability stand- 
ard with the related indicators to be fulfilled by the businesses that intend to use the "additional sustainability logo" under normal operating conditions (Regione Puglia, 2016).

\section{Step 1: Identification of criteria and selection} of the farm

The farm was selected based on the following criteria: location in the Puglia region (province of Bari); organic farm (whole organic surface); more surface of olive trees ( $>10 \mathrm{ha}$ ) in whole farm; the farmer should be an olive specialist according to the classification of agricultural holdings by type of farming ( $>50 \%$ of total standard output); parameters to define traditional farming (layout $5 \times 6 \mathrm{~m}$ or $6 \times 6 \mathrm{~m}$ or $7 \times$ $7 \mathrm{~m}$; 15-50 years old; local varieties: Coratina, Cima di Bitonto, Termite di Bitetto); diversity of crops (besides olive trees: almonds); professional farmer (entrepreneur); irrigation system; olive processing for third parties and sale of extra virgin olive oil by the farm itself; certification of quality systems; farmer's activities third party.

The case study was carried out in an organic traditional farm in Modugno, in the province of Bari, located in southern Italy. The site is characterized by a typical Mediterranean climate and it consisted of traditional organic farming with irrigation system. In the selected farm, olives for oil, table olives and almonds were grown. The land area was distributed as follows: 14.55 ha for olives trees for oil, 1.4 ha for olives tree for table olives and 2.2 ha for almond trees. The main varieties used for olive for oil are Coratina and Cima di Bitonto, Termite di Bitetto for table olives, while the variety used for almonds is Filippo Ceo. These local varieties had layout $6 \times 6$ $\mathrm{m}$ and are 25-30 years old. The farm is specialized in the cultivation of olives since $69 \%$ of its gross value is linked to olives. A microeconomic analysis of a local farm was performed, where processing was done by third parties. In order to favour an economically sustainable olive production, the selected farm aimed to improve profitability through investments in quality schemes. The farm was certified for the following standards: Organic certification, Protected Designation of Origin (PDO) and traceability procedure.
Step 2: Drafting the questionnaire for the selected farm and data collection

The economic data were collected through a questionnaire on organic olive oil and almond conducted in November 2018 that allowed to gather detailed information on: farm structure (type of orchards); inventory of machines, buildings, improvements and land labour (considered entirely as seasonal labour as well as the opportunity costs); variable costs and outputs by olive orchards type and almonds; other information (consultancy, insurance, participation to expos, certifications); information on market channels. The collected data referred to the two accounting periods (2 years) since hard pruning is commonly carried out every two years for olive trees which highly influences the alternate bearing. Missing or incomplete data were collected through official websites or interviews to local experts. The data related to the agricultural machinery efficiency and to the characteristics of olive plantations were compared with the Italian references to improve their accuracy. The collected data were used for evaluating each indicator.

\section{Step 3: Enterprise budget and economic indi-} cators

After the data collection, a Microsoft Office Excel sheet was designed to support the accounting functions such as crop budgeting for data compiling and elaboration. The main budgeting report was an enterprise budget considering three organic crops (olives for oil, table olives and almonds), where data was calculated using economic indicators such as gross margin (GM) and net farm income (NFI), in order to assess the economic sustainability of the farm. Variable costs included: inputs (e.g. pesticides, fertilizers, pruning, irrigation, fuel, harvesting, processing), seasonal labour and interest on previous costs. Fixed costs included: certification, permanent labour and depreciation cost. The economic sustainability indicators at farm level were: diversification index (DI) with its three components, investments or procedures adopted by farm, family work profitability index, and gross profitability per labour unit index. 
SWOT-analysis of the quality schemes' system in the Puglia region

The analysis of quality schemes in the Puglia region was performed with the help of the SWOT methodology, an effective strategic development tool that was used to evaluate strengths, weaknesses, opportunities, and threats of the quality schemes' system in Puglia. The main strengths, weaknesses, opportunities, and threats were identified and described. The strengths and weaknesses are considered internal to the system/sector and represent the present situation, while the opportunities and threats are external (e.g. represented by the environment external to the sector) and represent a possible future.

Table 1 presents a SWOT analysis regarding the implementation of quality schemes in the Puglia region. The SWOT framework was car- ried out through a collection of data from bibliographic information related to implementation of quality schemes in the Puglia region, by identifying external factors (i.e. opportunities and threats) and internal factors (i.e. strengths and weaknesses) (Lurati and Zamparini, 2018).

SWOT-analysis highlighted that Puglia has not a functioning system to ensure the sustainability. One of the main strengths identified by the study was that a theoretical methodology for sustainability exists. The data needed from the Puglia region and other sources are indeed available. This availability made easier to estimate economic sustainability indicators at farm level. Specifically, the analysis highlighted the weakness that no references exist about the sustainability methodology of the Programme "Agricoltura \& Qualità" which it is not implemented

Table 1 - SWOT analysis for regional quality schemes in the Puglia region.

\begin{tabular}{|c|c|}
\hline Strengths & Weaknesses \\
\hline - High quality, safe and traceable products & - High certification cost \\
\hline $\begin{array}{l}\text { - Availability of data (sources, references, data } \\
\text { bank) }\end{array}$ & $\begin{array}{l}\text { - Lack of a functioning system to ensure the } \\
\text { sustainability }\end{array}$ \\
\hline $\begin{array}{l}\text { Warranties for consumers / high requirement for } \\
\text { local production (region provides products with } \\
\text { high quality) }\end{array}$ & $\begin{array}{l}\text { - Prodotti di Qualità Puglia (PdQP) has lower } \\
\text { diffusion }\end{array}$ \\
\hline $\begin{array}{l}\text { High weight of BIO certification in the Puglia } \\
\text { region/large organic surface (importance of } \\
\text { organic farming) }\end{array}$ & $\begin{array}{l}\text { - Application of sustainability requires external } \\
\text { ways }\end{array}$ \\
\hline - High number of PDOs and GPIs in Puglia & - Lack of consumers' awareness \\
\hline Opportunities & Threats \\
\hline $\begin{array}{l}\text { - Increasing interest by consumers in certified } \\
\text { products }\end{array}$ & - Economic crisis/Instability of markets \\
\hline $\begin{array}{l}\text { Increasing demand for traditional and typical } \\
\text { products, fostering export }\end{array}$ & - Frauds/Imitation \\
\hline \multirow[t]{2}{*}{$\begin{array}{l}\text { - Regional Government support to rural } \\
\text { development and regional quality schemes }\end{array}$} & $\begin{array}{l}\text { - Limited level of education of stakeholders and } \\
\text { consumers }\end{array}$ \\
\hline & $\begin{array}{l}\text { - Lack of policy coordination in support of } \\
\text { methodology }\end{array}$ \\
\hline
\end{tabular}

Source: Own elaboration from our work during the year and literature review: Trienekens and Zuurbier, 2008; Barjolle et al., 2010; Janssen and Hamm, 2012; Scuderi and Pecorino, 2015; Comino and Ferretti, 2016; Palmisano et al., 2016; Perito et al., 2019. 
at this moment. Also, the awareness of sustainability, particularly for consumers and policymakers, is still limited.

\section{Results and discussion}

Results are presented and commented in two main parts. The first part focused on the gross margin and net farm income or three crop budgets and the enterprise budget, underlining profitability and performance of the farm. The results referred to two years of production and they were expressed in euro per hectare $(€ / \mathrm{ha})$. In the second part the selected economic indicators by the optional "sustainability" prerequisite guidelines were estimated, normalized and aggregated into composite indices. The final result determines that the selected farm is sustainable from the economic point of view or not. The indicator value concludes the probability to the use the logo "economic sustainability" by the selected organic olive oil farm, certified by Region Puglia.

\subsection{Economic dimension of case study}

The total farm gross margin, that is, the farm profit made after paying off its cost of goods sold, was approximately $42,000 €$, while gross margin of farm per hectare was $2,315 €$.

Per hectare, gross margin value tended to be the highest in organic almonds and the lowest in organic olives for table. Figure $3 b$ shows that almonds were the most profitable crops with $13,252 € /$ ha, while the less profitable (losses) were table olives crops with $836 € /$ ha (Figure $3 b)$. Almond crops generated higher income than the other crops, followed by olives for oil, the second most profitable crop in the farm. The third crop, table olives, showed a negative gross margin. This result was mainly due to the high human labour and pruning cost, as a result of its high density and canopy, confirming the insights of Mohamad et al. (2013). Since the quality of the olive's fruit has a crucial role in its marketing, the crops allocated to table olives was harvested manually. The study carried out by Famiani et al. (2014) confirmed that oil extracted from the mechanically harvested olives is of high quality and that the lowest harvesting cost for oil production is achieved thanks to harvesting machines. Anyway, the organic table olives orchard has lower yields than the orchard of olives for oil, particularly since the risk of losing olives because of insects is high. Moreover, the need for heavy annual pruning, manual har-

Figure 3 - The total gross margin of the farm and all organic crops cultivated in the farm expressed in euro for total surface (a) and comparison of the total gross margin between all organic crops cultivated in the farm expressed in $€ /$ ha (b).

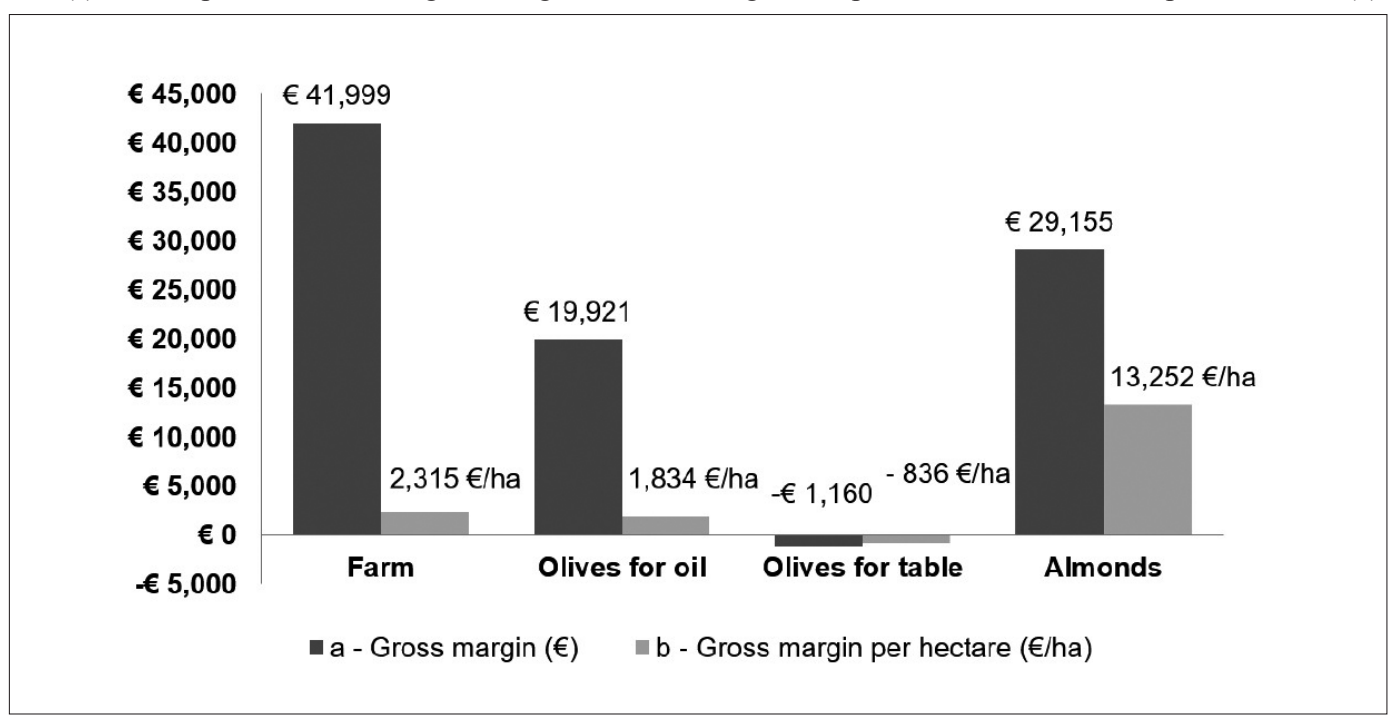


vesting and large amounts of water for irrigation involve high costs for inputs and labours, and although the unit price is slightly higher than the olive oil unit price, revenues are lower. Therefore, the profitability of table olives production is a delicate issue due to low prices and steadily rising production costs (Jimenez-Jimenez F. et al., 2015). In other words, low and sometimes negative profits, particularly in the years hit by more damages caused by insects and adverse climatic conditions, are not viable for the farm.

Average gross margin data of Rural Development Programme (RDP) Puglia 2014-2020 showed that gross margin per hectare of organic olive farm was $773 €$ which is lower the estimate produced by this study. As the gross margin is the difference between the total revenue and the total variable cost, it was needed to perform analyses of revenue and variable costs.

The total farm revenue was $113,897 €$, but the revenue of the farm per hectare was $6,278 €$. In the case of comparison of total revenue for each crop of the farm's total surface, the highest revenue was generated by olive oil with $21,838 €$ (14.55 hectares) (Figure 4). The crops of olives for oil generated $63 \%$ of total revenue.

Per hectare, the differences in revenue between the crops showed that the highest revenue was generated by almond (without hull) with $15,900 € /$ ha $(2.20$ hectare) compared to other crops as it is demonstrate in Figure 4b. Although the almond crop has a lower yield, its higher price explains why this crop reaches higher revenues per hectare $(18 € / \mathrm{kg})$. Figure $4 \mathrm{~b}$ shows that table olives had higher revenue than olives for oil. Previously, the data showed that table olives showed a negative gross margin. RDP 2014-2020 shows that the average revenue per hectare of the organic olive farm was $1,099 €$. After comparing with RDP, it can be concluded that the selected farm generated a higher revenue. As almonds generates a lot of revenue, the farmer may increase emphasis on this agri-food product. At the same time, the farmer may reduce emphasis on crops that did not generate high revenues.

Table 2 shows yield and subsidies for each crop cultivated in the farm. For the reasons mentioned above for table olives, the gross margin per hectare is negative. Consequently, yield in euro per hectare will be low. Several studies defined independence from external inputs as an indicator of economic sustainability. Farm dependency on external finance should be optimal to because it may hamper innovations (Spicka et al., 2019). RDP Puglia 2014-2020 showed

Figure 4 - The total revenue of the farm and all organic crops cultivated in the farm expressed in euro for total surface (a). Comparison of the total revenue between all organic crops expressed in $€ /$ ha (b).

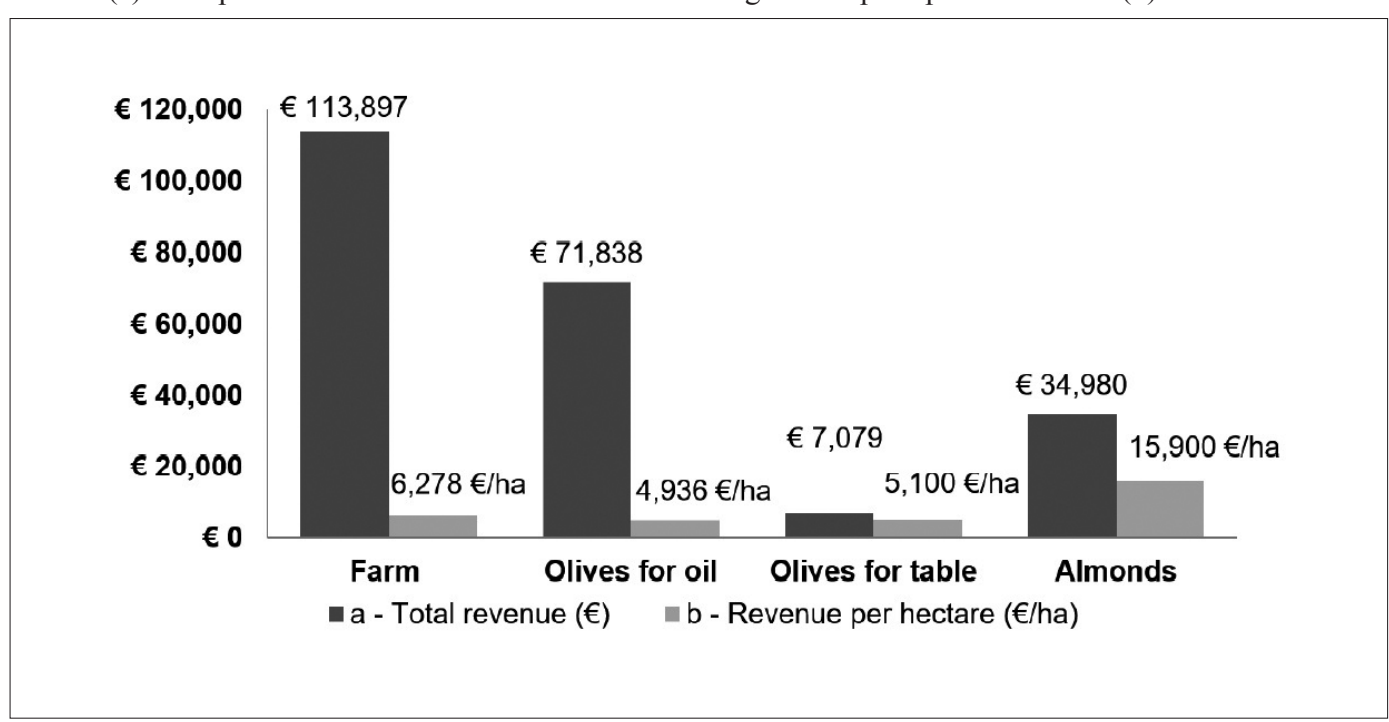


Table 2 - Yield, price and subsidies values of all crops.

\begin{tabular}{|c|c|c|c|}
\hline Crops & Olive oil & Table olives & Almonds \\
\hline Yield (ton/ha) & 7.43 & 4.86 & 5.50 \\
\hline Yield (€/ha) & 57,183 & 5,830 & 33,000 \\
\hline $\begin{array}{c}\text { Subsidies } \\
(\text { E/ha) }\end{array}$ & 1,007 & 900 & 900 \\
\hline
\end{tabular}

that average yield per hectare in an organic olive farm was $3.3 €$. The selected farm has generated a high yield. In Puglia, the available data on almonds are amalgamated in the range of stone fruits, which makes it obscured.

The total farm variable cost was $71,898 €$ and variable cost of farm per hectare was 3,963 $€$ (Figure 5a). RDP 2014-2020 showed that the average variable cost per hectare of organic olive farm was $325 €$. Organic almond was the crop with the lowest production cost (Figure $11 \mathrm{~b})$. The total variable cost of organic almonds was mainly influenced by the lower fertilization, labour, pest management, pruning and fuel costs.

The total farm input cost was $29,377 €$ and, per hectare, farm input cost was 1,619 € (Fig- ure 6a). Based on input cost, the almond crop followed a similar rule as the total variable cost (Figure 6b). The almond crop had the lowest input cost while table olives crop had the highest input cost. According to the analysis, almond crop showed lower requirements for fertilization and pest management.

Inputs needed for the crop allocated to table olives were higher than the other crops except soil operation and processing (not applicable).

The pruning and harvesting costs had the highest impact on the total input cost. On the contrary, the other agricultural activities had a lower influence on the total input cost. The higher input cost of pruning was was linked to the crop of table olives due to the higher number of trees per hectare as well as its morphological characteristics. These data are in accordance with a study carried out by Mohamad et al. (2013) which highlighted that the olive pruning cost was higher due to its high density and canopy. The almond crop had the lowest input cost of pruning. The harvesting cost was lower in crop of olives for oil due to less hours dedicated to labour and a lower use of shakers. On the contrary, the harvesting cost was higher in the crop for table olives due to higher working hours. The crop allocated to table olives was traditionally

Figure 5 - Total variable cost of the farm and all organic crops cultivated in the farm expressed in euro for total surface (a). Comparison of the total variable cost between all organic crops expressed in $€ /$ ha (b).

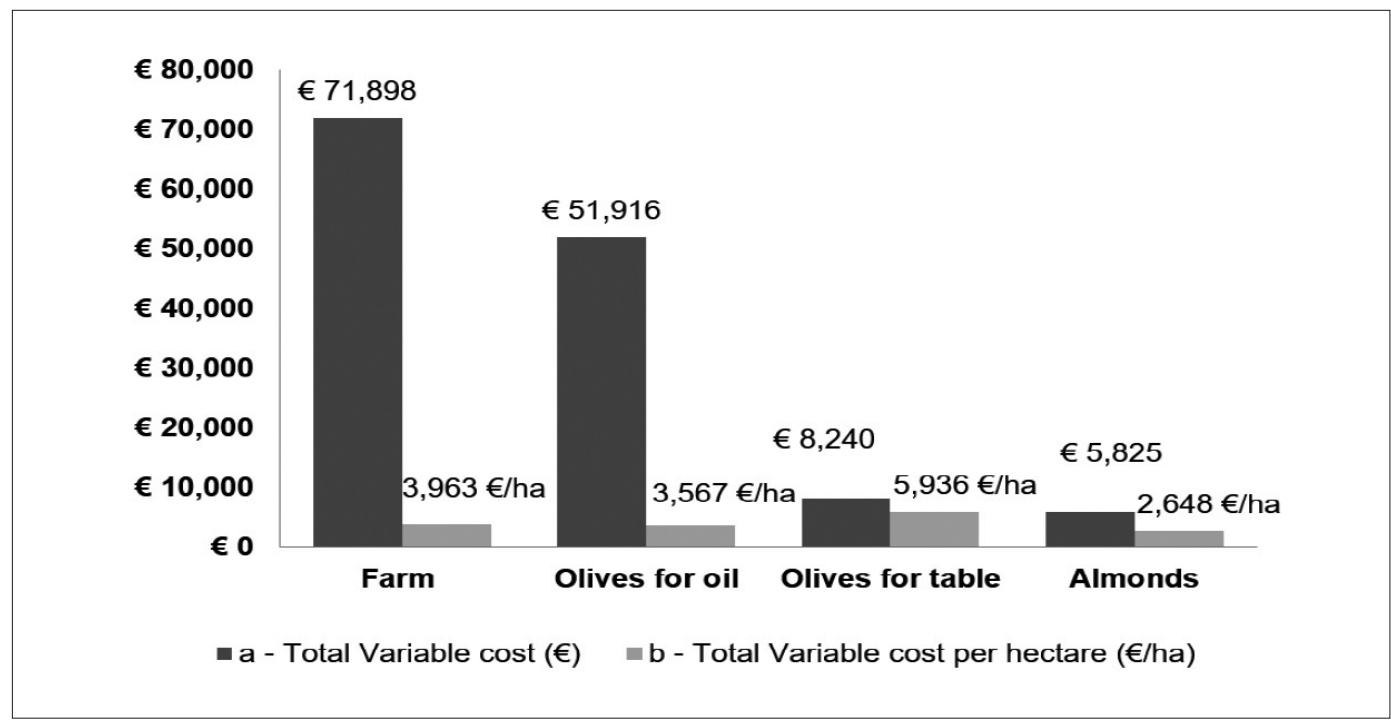


harvested manually since the quality of olive's fruit has an essential role in its marketing. The study carried out by Famiani et al. (2014) concluded that oil obtained from the mechanically harvested olives is always of high quality. Also, it confirmed that the lowest harvesting cost for oil was obtained with the harvesting machine. Processing cost was applicable for crops for olive for oil and almonds.
The total labour cost was $40,767 €$ and labour cost per hectare was $2,247 €$ (Figure 7a). Labour cost per hectare turned out to be the highest in the crop for table olives and the lowest in almond crop (Figure 7b). This is a result of the pruning and harvesting cost. During harvesting of the crop for table olives, to avoid damage of olive fruit that can reduce fruit quality both, it required more hours of

Figure 6. Total input cost of the farm and all organic crops cultivated in the farm expressed in euro for total surface (a). Comparison of the total input cost between all organic crops expressed in $€ /$ ha (b).

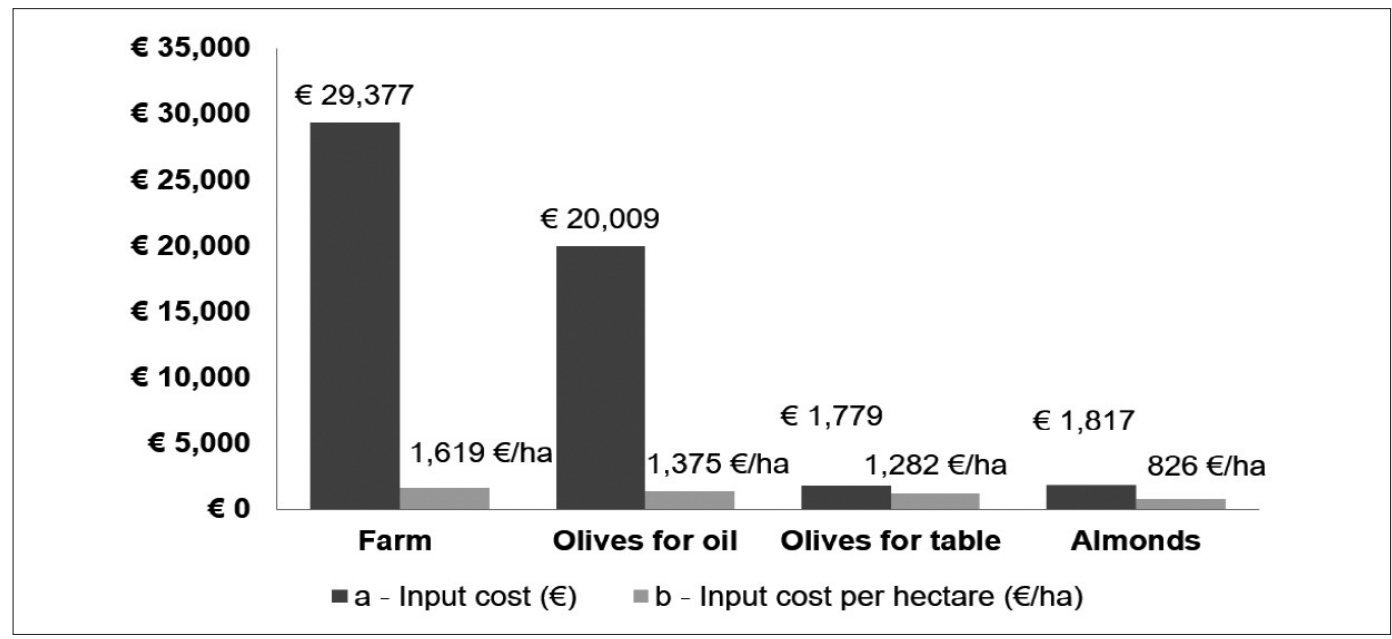

Figure 7 - Total labour cost of the farm and all organic crops cultivated in the farm expressed in euro for total surface (a). Comparison of the total labour cost between all organic crops expressed in $€ /$ ha (b).

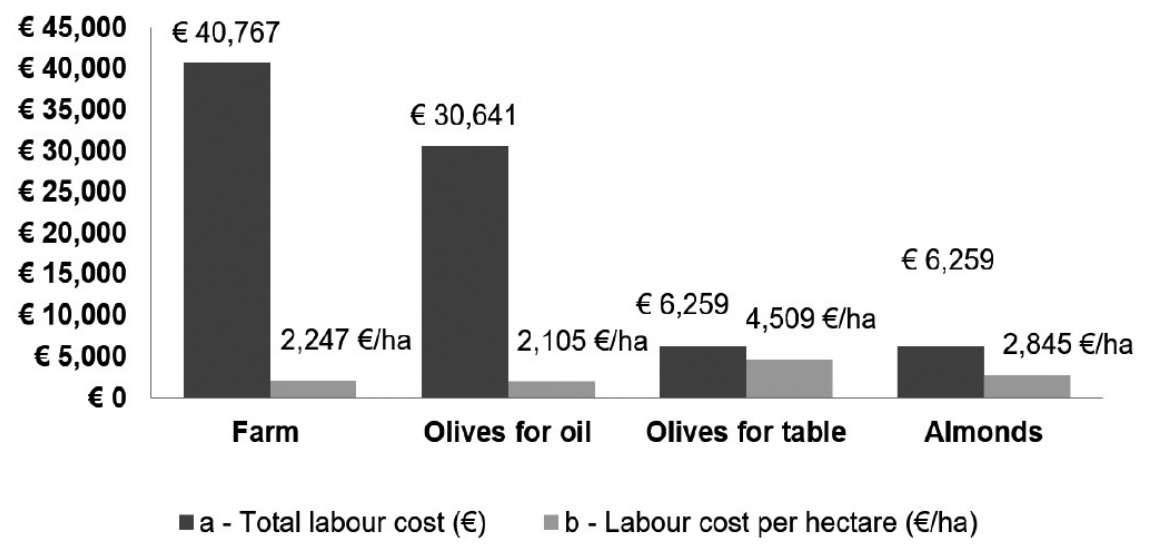


labour. Another explanation was the high density of table olives per hectare.

The production costs for the crop allocated to olives for oil production was $3,866.4 € /$ ha, whereas the costs for the crop of table olives was $6,382.9 € /$ ha and 2,842 $€ /$ ha for the almond crop. Higher revenues and lower production costs were the reasons why the almond crop was more profitable.

The ratio gross margin on yield indicated that to produce one ton of olives for oil, the farmer earned $184 € /$ ha. Moreover, to produce one ton of almond crop the farmer earned 2,409 $€ /$ ha. This ratio confirmed once again that the almond crop was the most profitable one, contrary to the crop for table olives, which had the lowest revenues. Labour on variable cost ratio showed that for each $1 €$ paid as a variable cost the farmer paid $0.57 €$ as labour cost. Comparison between the crops showed that the crop for olives for oil had the lowest labour on variable cost ratio. For 1 euro paid as a variable cost, $0.55 €$ was paid as a labour cost for the crop for table olives, showing that the portion of labour cost was the highest for the crop for table olives. This crop needed more labour for its growing operations since the density of trees for hectare was higher. Input on variable cost ratio pointed out that for each $1 €$ paid as a variable cost the farmer paid $0.41 €$ as input. Results showed that the value of this ratio was higher in the crop for table olives, meaning that the portion of input cost in the crop for table olives was higher which required a more costly input. Thus, for $1 €$ paid as variable cost, $0.16 €$ was paid as input cost in case of table olives. Similarly as for labour on variable costs ratio, the crop for table olives had a lower portion of inputs. Revenue on variable cost ratio indicated that for each $1 €$ paid as a variable cost the farmer earned $1.58 €$ as revenue. For the almond crop, which was the most profitable crop in the farm, for $1 €$ paid as variable cost the farmer earned $2.73 €$ as revenue. Once again, increased selling price proved that almond can be highly profitable, especially with lower cost as resulted in this study. Revenue on labour cost ratio showed that for each $1 €$ paid as a labour cost the farmer earned $2.79 €$ as revenue. This ratio indicated that for each $1 €$ paid as labour cost, the farmer earned $2.54 €$ as revenue for the almond crop. This shows that the almond crop had the highest labour efficiency.

\subsection{Economic sustainability assessment and benchmark values}

The results for the sustainability indicators are presented below.

\subsubsection{Diversification index}

Since three products were grown in the farm (olive oil, table olives and almonds) the score of this component was equal to 0.75 points (Figure 8 ). After multiplying this value by the coefficient 0.5 , the value of current component turned out to be equal to 0.375 .

The crop of olives for oil accounted for $63 \%$ of the farm's production value. It is in accordance with the Commission Regulation (EC) No $1242 / 2008$ that a farm is considered specialized in olives when its olive production represents more than $50 \%$ of the total production. A score of 0.43 (Figure $8 \mathrm{~b}$ ) was attributed to the $63 \%$ percentage. Then, it was normalised by multiplying it by a coefficient of 0.2 . The farm had only agricultural activity. In this case it was attributed the score equal to 0.3 (Figure $8 \mathrm{c}$ ) which was normalized by multiplying it by a coefficient 0.2 . Since there was only one agriculture activity carried out in the farm, there is low resistance to commercial risks (Baccar et al., 2019). Finally, the value of diversification index (DI) was 0.52 that turned out to be higher than the sustainability benchmark. The value of index was put on the graphic of sustainability benchmark.

The higher is the value of DI the higher the farm would be resilient to external factors. According to a study carried out by Kazakova-Mateva and Radeva-Decheva (2015), the diversification of crops has a positive impact in increasing the resilience of farms to climate change and environmental pressures. Furthermore, it enhances the technical efficiency in farm, improves their economic results as the results of our study suggest. This is consistent with what was suggested by Baccar et al. (2019) and Ogundari (2013) about the fact that the diversification of activities and crops make farms more flexible and resil- 
Figure 8 - a) The number of agriculture products realized in the farm; b) Distribution of turnover among different products and services; c) Heterogeneity or affinity of products and services supplied.

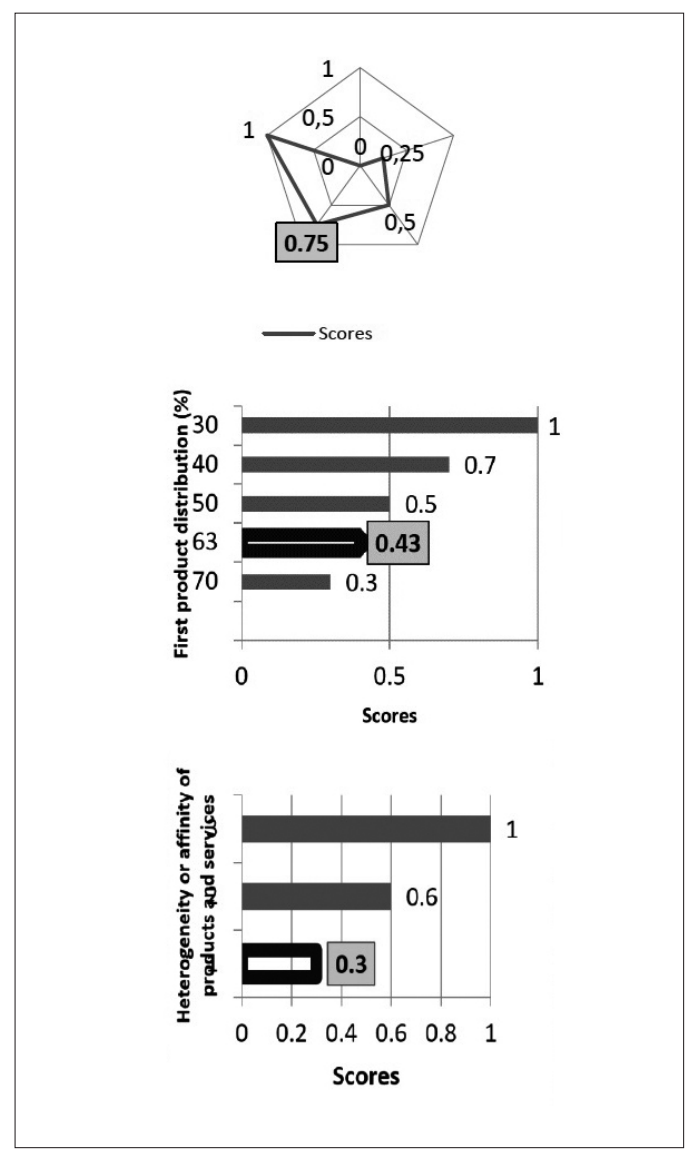

ient. Besides that, it contributes to establishing money reserves which increase thanks to diverse and spread out sources across the year. This flexibility, together with the lack of loans, renders the farm more economically independent.

\subsubsection{Investments or procedures adopted by farm}

Investments or procedures adopted by farm carried out in the last 5 years is 0.3 , which turned out to be lower than the sustainability benchmark (Figure 9).

Farmer has invested in the improvement of sustainability performance, but it needs to invest more. However, the farmer has the resources to make larger investments.
Figure 9 - The procedures or investments adopted by the farm.

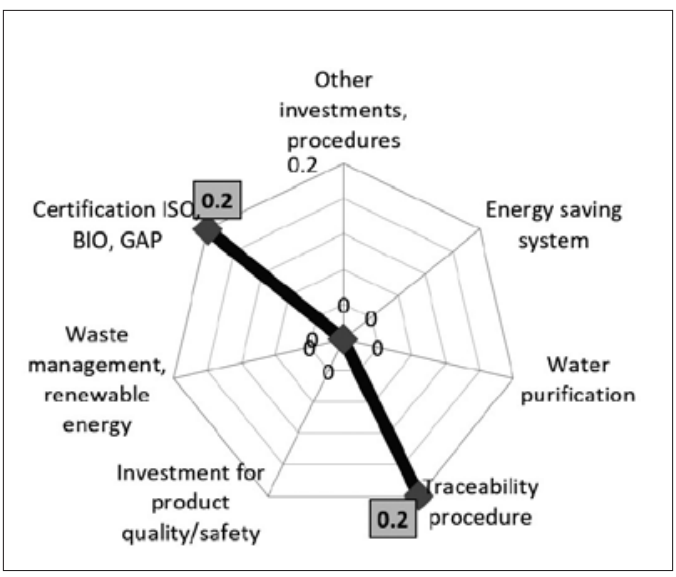

\subsubsection{Family work profitability index}

The updated benchmark for family work profitability index was $19,930 €$ (ISTAT, 2019) whose attributed score is equal to 0.5 .

In the selected farm, the value of family work profitability index was $25,220 €$ corresponding to the score of 0.63 that turned out to be higher than the sustainability benchmark.

The graphical representation of the sustainability indicator assessment results is illustrated in Figure 10. The sum of the results obtained from the individual indicators provided an economic sustainability indicator whose score was equal to 0.6 .

Figure 10 - Assessment of economic sustainability indicators at farm level.

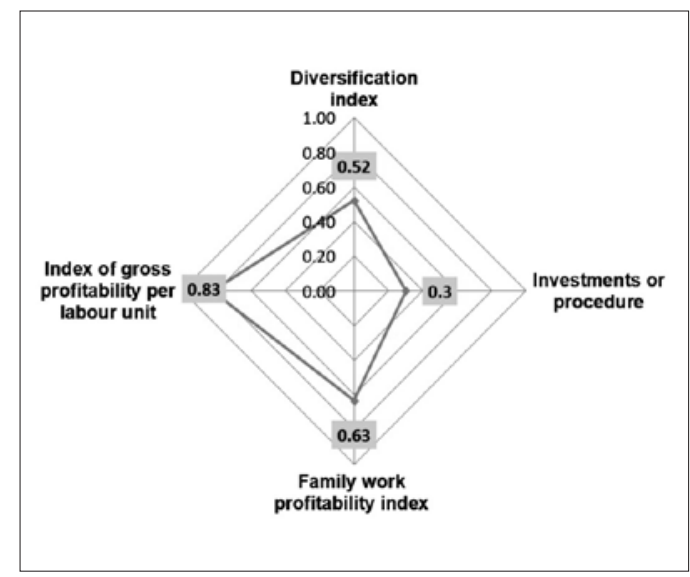


The highest value among the economic sustainability indicators was index gross profitability per labour unit due to high revenue generated in the farm. The lowest sustainability indicator was investments/procedures adopted by farm because of the low number of investments made. It confirms the conclusions from the previous study suggesting that the economic sustainability can be achieved through means of farm investments, as well as low-cost activities that enhance environmental performance and generate positive social effects without damaging economic viability (Majewski, 2013). These investments should not exceed the financing abilities of the farm. The economic sustainability value (0.57) was put on the graphic of sustainability benchmark and it resulted higher than sustainability benchmark (Figure 11).

According to this result, the case study of an organic olive oil farm in the Puglia region is sustainable from economic point of view. Taking into consideration the strong diversity of agricultural farms (e.g. the scale of production, level of technological advancement), this value is moderately good. It should be noted that due to imperfect farmer decisions and competition between sustainability objectives such as economic and environmental, it is practically hard to reach the maximum sustainability value even in the case of a perfect farm as confirmed by Majewski (2013). In this overall frame, factors correlated to the production system and responsibility of farmers (e.g. decisions on what to produce, cropping practices, capital held, etc.) largely determine the economic sustainability farm and, consequently, its sustainability (Baccar et al., 2019). Since the economic sustainability indicator value was above the benchmark sustainability, the traditional organic farm can use the "additional sustainability logo", certified by the Puglia Region during the transitional

Figure 11 - Economic sustainability value.

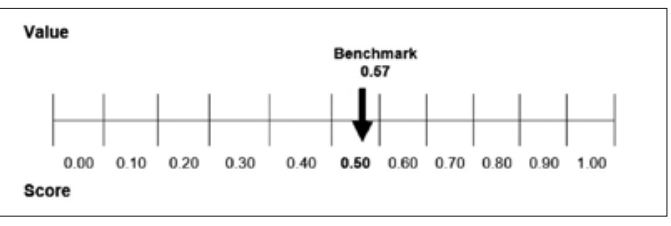

phase. Additionally, it is stressed that only the "economic sustainability" symbol can be used, instead of the general lettering "sustainability".

\section{Conclusion}

Sustainability is the focus of the CAP. The CAP aims at ensuring sustainability with respect to both economic and social and environmental aspects. The CAP currently offers farmers a number of ways to contribute to our climate and environmental objectives. In the future, the CAP post-2020 will offer more opportunities to farmers in order to create Eco-Schemes for additional incentives for climate and environment-friendly farming practices, as well as for agri-environmental climate measures and investments (European Commission, 2020a).

In order to implement the EU Biodiversity Strategy for 2030 "Bringing nature back into our lives", the agroecology, therefore the organic farming, can provide healthy food while maintaining productivity, increase soil fertility and biodiversity, and reduce the footprint of food production. Moreover, organic farming in particular holds great potential for farmers and consumers alike (European Commission, 2020b). As a matter of fact, the EU Biodiversity Strategy for 2030 highlights, among the key actions, the elaboration and implementation of the Action Plan for Organic Farming for 2012-2026 that proposes a great challenge: at least $25 \%$ of the EU's agricultural land must be organically farmed by 2030 .

Embedding the concept of sustainability in the way we produce and consume our food will bring benefits for all the actors in the food chain and in particular for farmers (European Commission, 2020c). The economic sustainability of an organic farm is the fundamental issue for the feasibility of the enterprise and the development of organic sector, and moreover, organic agriculture will bring important benefits and positive impacts for the implementation of the aforementioned eco-friendly policies.

The main goal of this study was to investigate the economic sustainability of a case study, a traditional organic olive oil farm in the Puglia region (South-eastern Italy), through the as- 
sessment of the economic sustainability indicators selected in the Programme "Agricoltura \& Qualità" of the Puglia Region. In this section, the main ideas resulting from economic analysis are listed, followed by the assessment of the economic sustainability of the farm.

The economic assessment through the gross margin showed that the profit of the selected traditional organic olive farm is higher than average gross margin of olive farms of Puglia according to the Rural Development Programme for Puglia 2014-2020. The farm resulted as a profitable enterprise. Profitability differs according to the crops of the farm. Per hectare, the economic assessment showed that almond is the most profitable crop with higher revenue, whereas the variable costs are higher in table olives and the inputs are higher in olives for oil.

Better management of the inputs costs for table olives should be implemented to reduce the production costs and increase the revenues. The use of farm resources and more extensive agricultural practices helps to generate lower production costs. The quantities of nitrogen fertilizer purchased can be moderated through the use of legumes. The mechanized pruning increases the efficiency of labour reducing of the cost of pruning. Furthermore, the use of shakers for mechanized harvesting increases olive production and increases the quality of olive oil, avoiding the harvesting from the ground.

The economic sustainability assessment of the case study in the territorial context using the results economic indicators showed that the selected farm in the Puglia region is sustainable from an economic point of view. In addition, the traditional organic olive oil farm can use the "additional sustainability logo", certified by the Puglia Region, but it can be stressed only through the economic sustainable symbol "economic sustainability" instead of the general lettering "sustainability" since only the economic sustainability of the farm was assessed.

The assessment of the economic sustainability indicators designed in the pilot project reveals that diversification index of organic olive oil farm is higher than sustainability benchmark since the farm produces three different products (e.g. olive oil, table olives and almonds); the first product has a value greater than $63 \%$ of the farm production value; and, it has only agricultural activity.

In order to improve the quality of products and sustainability performance, and also to reduce the negative externalities of the production activity, the farmer has invested in PDO, an organic certification and traceability procedure. However, its investments or procedures index is lower than the sustainability benchmark. To increase this indicator and to improve sustainability of farm, the farmer needs to adopt more procedures or make more investments.

The third economic sustainability indicator return rate of family labour is above sustainability benchmark. The last indicator selected from the methodology, namely, the index of gross profitability per labour unit, is higher than the sustainability benchmark.

This assessment tool can support decision-makers in improving the sustainability of their organic production systems.

The SWOT-analysis highlights that Puglia has not a functioning system to ensure sustainability. Sustainability awareness, particularly for consumers and policymakers, is still limited.

It can be concluded that economic sustainability indicators are suitable and measurable at farm level. Most of the data needed to assess sustainability are available.

In this prospect, the suggestions are to foster the implementation of the methodology on a larger scale for economic sustainability, and also for environmental, socio-cultural and health-nutritional dimensions using more human and financial resources, hence, supporting tools to enable an assessment of various scenarios combining technical, economic and environmental indicators. Furthermore, the Puglia Region should invest in sustainability since it is an important opportunity to improve and develop the agri-food system, to fight the economic crisis.

\section{References}

Agriaffaires, 2019. Macchine agricole. https://www. agriaffaires.it/ (July 2019).

Baccar M., Bouaziz A., Dugué P., Gafsi M., Le Gal P.Y., 2019. The determining factors of farm sustain- 
ability in a context of growing agricultural intensification. Agroecology and sustainable food systems, 43(4): 386-408.

Barjolle D., Damary P., Schaer B., 2010. Certification schemes and sustainable rural development: Analytical framework for assessment impacts. Paper presented at the International Seminar EAAESYAL "Spatial Dynamics in Agrifood Systems: Implications for Sustainability and Consumer Welfare", 27-29 October, Parma, University of Parma.

BioBank Open Project, 2018. Sistema integrato di gestione dei dati sul biologico pugliese e del relativo sistema di controllo.

Brundtland G.H., 1987. Towards sustainable development. In: Hauff H. (ed.), Our common future. The World Commission on Environment and Development. Oxford: Oxford University Press, pp. 41-58.

Capone R., El Bilali H., Bottalico F., 2016a. Assessing the sustainability of typical agri-food products: insight from Apulia Region, Italy. New Medit, 15(1): 28-35.

Capone R., Malorgio G., Cardone G., El Bilali H., Bottalico F., Debs Ph., 2016b. Towards a common understanding of agri-food products economic sustainability: insights from Apulia region, Italy. In: 158th EAAE Seminar "Euro-Mediterranean cooperation in sustainable agriculture and food security: policies, sustainability, marketing and trade", Book of Abstracts, 8-9 September, Mediterranean Agronomic Institute of Chania (CIHEAM-MAICh), Chania, Crete, Greece, pp. 10-11.

Comino E., Ferretti V., 2016. Indicators-based spatial SWOT analysis: Supporting the strategic planning and management of complex territorial systems. Ecological Indicators, 60: 1104-1117.

CREA, 2020. L'agricoltura italiana conta 2019. Roma: CREA - Centro di ricerca Politiche e Bioeconomia.

European Commission, 2008. Commission regulation (EC) No 1242.2008 of 8 December 2008 on establishing a Community typology for agricultural holdings. Official Journal of the European Union, 335: 3-24.

European Commission, 2017. CAP explained. Direct payments for farmers 2015-2020. Luxembourg: Publications Office of the European Union.

European Commission, 2020a. How the future CAP will contribute to the EU Green Deal, Facsheet. Brussels, May 2020.

European Commission, 2020b. Communication from the Commission to the European Parliament, the Council, the European Economic and Social Committee and the Committee of the Regions, EU Bio- diversity Strategy for 2030, Bringing nature back into our lives, $\operatorname{COM(2020)~} 380$ final, Brussels, 20.5.2020.

European Commission, 2020c. EU Green Deal: benefits for farmers, Factsheet. Brussels, May 2020.

European Union, 2013. Regulation (EU) No $1305 / 2013$ of the European Parliament and of the Council of 17 December 2013 on support for rural development by the European Agricultural Fund for Rural Development (EAFRD) and repealing Council Regulation (EC) No 1698/2005. Official Journal of the European Union, 347: 487-548.

Eyhorn F., Muller A., Reganold J.P., Frison E., Herren H.R., Luttikholt L., Mueller A., Sanders J., Scialabba N.E., Seufert V., Smith P., 2019. Sustainability in global agriculture driven by organic farming. $\mathrm{Na}$ ture sustainability, 2(4): 253.

Famiani F., Farinelli D., Rollo S., Camposeo S., Di Vaio C., Inglese P., 2014. Evaluation of different mechanical fruit harvesting systems and oil quality in very large size olive trees. Spanish Journal of Agricultural Research, 12(4): 960-972.

FAO, 2014. SAFA - Sustainability assessment of food and agriculture systems. Guidelines. Version 3.0. Rome: FAO.

Iofrida N., Stillitano T., Falcone G., Gulisano G., Nicolò B.F., De Luca A.I., 2020. The socio- economic impacts of organic and conventional olive growing in Italy. New Medit, 19(1): 117-131. https://doi. org $/ 10.30682 / \mathrm{nm} 2001 \mathrm{~h}$.

ISTAT, 2019. Annuario statistico italiano. Rome: ISTAT.

Janssen M., Hamm U., 2012. Product labelling in the market for organic food: Consumer preferences and willingness-to-pay for different organic certification logos. Food quality and preference, 25(1): 9-22.

Jimenez-Jimenez F., Blanco-Roldan G., Castillo-Ruiz F., Castro-Garcia S., Sola-Guirado R., Gil-Ribes J., 2015. Table Olives Mechanical Harvesting with Trunk Shakers: Orchard Adaptation and Machine Improvements. Chemical Engineering Transactions, 44: 271-276.

Kazakova-Mateva Y., Radeva-Decheva D., 2015. The role of agroecosystems diversity towards sustainability of agricultural systems. Paper presented at the 147th EAAE Seminar 'CAP impact on economic growth and sustainability of agriculture and rural areas', October 7-8, Sofia, Bulgaria.

Lurati F., Zamparini A., 2018. Communication SWOT Analysis. In: Health R.L., Johansen W. (eds.), The International Encyclopedia of Strategic Communication. Hoboken: John Wiley \& Sons, vol.1, pp. 272-280. 
Majewski E., 2013. Measuring and modelling farm level sustainability. Visegrad Journal on Bioeconomy and Sustainable Development, 2(1): 2-10.

Malorgio G., Adinolfi F.C., Capitanio F., Cardone G., 2015. Valutazione della sostenibilità economica dei prodotti tipici pugliesi e relativi indicatori. In: $R e$ port "Agricoltura \& Qualità" of Regione Puglia. Valenzano: CIHEAM-Bari, pp. 169-278.

MIPAAFT (Ministero delle politiche agricole alimentari, forestali e del turismo), 2019. Bioreport 2017-2018. L'agricoltura biologica in Italia. Rome: MIPAAFT.

Mohamad R.S., Bteich M.R., Cardone G., Marchini A., 2013. Economic analysis in organic olive farms: the case of the ancient olive trees in the rural parkland in Apulia. New Medit, 12(4): 55-61.

Ogundari K., 2013. Crop diversification and technical efficiency in food crop production: A study of peasant farmers in Nigeria. International Journal of Social Economics, 40(3): 267-288.

Palmisano G.O., Govindan K., Boggia A., Loisi R.V., De Boni A., Roma R., 2016. Local Action Groups and Rural Sustainable Development. A spatial multiple criteria approach for efficient territorial planning. Land use policy, 59: 12-26.

Perito M A., Sacchetti G., Di Mattia C.D., Chiodo E., Pittia P., Saguy I.S., Cohen E., 2019. Buy local! Familiarity and preferences for extra virgin olive oil of Italian consumers. Journal of Food Products Marketing, 25(4): 462-477.

Ramankutty N., Mehrabi Z., Waha K., Jarvis L., Kremen C., Herrero M., Rieseberg L.H., 2018. Trends in global agricultural land use: implications for environmental health and food security. Annual review of plant biology, 69: 789-815.

RDP (Rural Development Programme), 2014. Agriculture and rural development 2014-2020. European Commission.

Reganold J.P., Wachter J.M., 2016. Organic agriculture in the twenty-first century. Nature plants, 2(2): 15221.

Regione Puglia, 2016a. Determinazione del dirigente sezione alimentazione 2 maggio 2016, n. 71 Deliberazione della Giunta Regionale n. 2210 del 09/12/2015. Riconoscimento del Regime di Qualità regionale "Prodotti di Qualità Puglia". Disciplinari di produzione. Approvazione. Bollettino Ufficiale della Regione Puglia, 60, 26/05/2016.

Regione Puglia, 2016b. Determinazione del dirigente sezione alimentazione 3 maggio 2016, n. 76 Deliberazione della Giunta Regionale n. 2210 del 09/12/2015. Riconoscimento del Regime di Qualità regionale "Prodotti di Qualità Puglia". Linea Guida per il riconoscimento del requisito facoltativo "Sos- tenibilità”. Approvazione. Bollettino Ufficiale della Regione Puglia, 60, 26/05/2016.

RICA (Rete di informazione contabile agricola), 2018. Risultati economici delle aziende agricole. Roma: CREA-Centro di ricerca Politiche e Bioeconomia.

Saker Ben Abdallah, Saida Elfkih, Carlos Parra-López, 2018. A sustainability comparative assessment of Tunisian organic and conventional olive growing systems based on the AHP methodology. New Medit, 17(3): 51-68. DOI: 10.30682/nm1803e.

Saponari M., Giampetruzzi A., Loconsole G., Boscia D., Saldarelli P., 2018. Xylella fastidiosa in olive in Apulia: Where we stand. Phytopathology, 109(2): 175-186.

Scuderi A., Pecorino B., 2015. Protected designation of origin (PDO) and protected geographical indication (PGI) Italian citrus productions. Acta Horticolturae, 1065: 1911-1917.

Shelef O., Fernández-Bayo J.D., Sher Y., Ancona V., Slinn H., Achmon Y., 2018. Elucidating local food production to identify the principles and challenges of sustainable agriculture. In: Galanakis C.M. (ed.), Sustainable food systems from agriculture to industry. Cambridge, MA: Academic press, pp. 47-81.

SINAB (Sistema d'Informazione Nazionale sull'Agricoltura Biologica), 2018. L'agricoltura biologica in Italia 2018. Roma: SINAB.

Spangenberg J.H., 2005. Economic sustainability of the economy: concepts and indicators. International Journal of Sustainable Development, 8(1-2): 47-64.

Spicka J., Hlavsa T., Soukupova K., Stolbova M., 2019. Approaches to estimation the farm- level economic viability and sustainability in agriculture: A literature review. Agricultural Economics, 65(6): 289-297.

Stillitano T., De Luca A.I., Falcone G., Spada E., Gulisano G., Strano A., 2016. Economic profitability assessment of Mediterranean olive growing systems. Bulgarian Journal of Agricultural Science, 22(4): 517-526.

Šūmane S., Kunda I., Knickel K., Strauss A., Tisenkopfs T., Des los Rios I., Rivera M., Chebach T., Ashkenazy A., 2018. Local and farmers' knowledge matters! How integrating informal and formal knowledge enhances sustainable and resilient agriculture. Journal of Rural Studies, 59: 232-241.

Suolo e Salute, 2019. Listini. https://www.suoloesalute.it/ (July 2019).

Trienekens J., Zuurbier P., 2008. Quality and safety standards in the food industry, developments and challenges. International Journal of Production Economics, 113(1): 107-122. 